\title{
The ebb and flow of homophobia: a gender taboo theory
}

\author{
David Plummer \\ Griffith University, Australia \\ d.plummer@griffith.edu.au
}

\begin{abstract}
A key challenge for gender theory and practice is to explain the circumstances in which homophobia either intensifies or declines. In addition to the important theoretical implications of such an explanation, being able to clearly delineate the mechanisms that drive the ebb and flow of homophobia raises the prospect that one day it might be possible to eradicate this important antisocial problem. But understanding the underlying drivers entails the development of a satisfactory body of theory to explain the existence of homophobia - a body of theory that may well be called on to explain different homophobias in different cultural settings that span the gender spectrum. As discussed, various proposals have been made for alternative terminologies and associated candidate theories that are intended to explain homophobia better. However, none seems to have articulated a sufficiently compelling case to be considered definitive, while others simply fail to accord with everyday homophobic experiences. The purpose of this paper is threefold. First, to propose a set of criteria that need to be satisfied if a theory is going to provide a robust explanation for the ebb and flow of homophobia(s). Second, to explore whether gender taboos offer a coherent theoretical basis for explaining the existence of, and the power behind homophobia. Finally, the analysis looks to shifting gender relations as a possible explanation for the ebb and flow of homophobia.
\end{abstract}

\section{Keywords}

masculinity; masculinities; inclusive masculinities; masculine taboos; gender roles; gender taboos; homophobia; homophobia-phobia; homophobiaphobia; homohysteria; gender taboo theory; homophobia theory

\section{Introduction: The ebb and flow of homophobia}

Homophobia is an important social problem that exacts a heavy toll on the wellbeing of men and women around the world (Berrill, 1992; Tin, 2008). The prospect of being able to better understand what drives homophobic prejudices and what causes them to fluctuate, raises the possibility that it might be possible to intervene and ultimately to be free of these harmful antisocial phenomena. In their important work, McCormack and Anderson (2014) have found evidence for declining levels of homophobia in circumstances where homophobia was previously well established, especially in all male institutions, schools, colleges and sporting teams in the US and UK. At around the same time, McCann reported evidence from Australian men that suggests that homophobia can be unlearned (McCann, Minichiello \& Plummer, 2009). Moreover, there is also evidence that reductions in homophobia can be circumstantial and highly circumscribed. For example, in Anglophone cultures, homophobia typically interdicts intimate male-male contact in public spaces, but this interdiction can be readily suspended in the case of members of a winning football team, who are momentarily free to embrace, cry and kiss each other on the playing field in front of spectators to celebrate a hard fought victory (for more, see Plummer, 1999, pp. 257-266). 
There is also evidence for the reverse: that homophobia can intensify, sometimes dramatically so, from a low base. For example, recent escalations of homophobia in Nigeria and Uganda have been widely reported (for general comments on homophobia in Africa see Awondo, Geschiere, Reid, 2012; Ireland, 2013; Jonas 2013; Gay Rights: legalized homophobia, 2013; For Nigeria see Human Rights: Nigeria's controversial bill, 2014; For Uganda see Xie, 2010; Human Rights/Homophobia: Uganda, 2011; Boyd, 2013; and Human Rights: Uganda passes anti-gay law, 2014). These developments culminated in their respective parliaments passing draconian new laws against homosexuality, which very nearly included the death penalty. Meanwhile, parts of the Caribbean have witnessed rising levels of homophobia associated with a growth of violent themes in musical genres that were previously noted for their laid back nature (see Stop Murder Music, 2004; Bakare-Yusuf, 2006; West \& Cowell, 2014). Europe is no stranger to these escalations either. Following a period of relative liberalization, homophobia intensified in Germany during the 1930s where homosexual men were among the targets for internment in Nazi concentration camps (Plant, 1988; Grau, 1993). In more recent times, homophobia has re-emerged in post-soviet Russia, a situation that was highlighted by activists during the recent Sochi Winter Olympics (Underwood, 2011).

Wide cultural variations in the codes that govern acceptable and unacceptable homointimate practices between men are also well documented (by homointimate, I am referring to closeness and intimacy between men while trying not to invoke unjustified connotations of eroticism or sexuality). At one extreme are traditions, notably in Britain and former colonies, where trivial hints of male intimacy have traditionally been sufficient to trigger homophobic reactions, whereas similar behaviors between a man and a woman would generally be viewed as acceptable (for discussion see Anderson, Adams \& Rivers, 2012; for country-specific details see Tin, 2008). In contrast, despite some Middle Eastern countries still imposing the death penalty for homosexual acts (for a summary of countries and punishments, including the death penalty, see Tin, 2008, p. 11), it is the norm for men to hold hands, embrace, and even to greet each other with a public kiss, while similar behaviors between a man and a woman would be unacceptable (Schmitt \& Sofer, 1992). The part of the world I am writing from (on the edge of Melanesia) is home to even greater contrasts. In many Melanesian coastal communities most notably Papua New Guinea, traditional initiation rites entailed the insemination of initiates apparently in the belief that semen was a powerful source of masculinity and exposure to semen was a necessary step on the road to mature manhood (Herdt, 1993). These practices do not appear to have invoked homophobia as we know it nor to have feminized participants; indeed, they only became problematic with the arrival of Western missionaries as recently as the early $20^{\text {th }}$ century (Herdt, 1993, pp. 18-20).

Each of these diverse examples gives an idea of the extent of the possible variations in levels of homophobia and the variety of behaviors and circumstances known to provoke homophobic reactions. For the purposes of the present paper, these cases serve to demonstrate that (i) homophobia can be readily suspended under certain circumstances in otherwise homophobic settings; (ii) the boundary between acceptable and unacceptable malemale intimacy is mobile and is located at different places in different cultures, sometimes provoking homophobia, sometimes not; (iii) that in other settings, even the most homointimate initiation rituals can be associated with dominant masculinity and with no evidence of feminization or homophobic reactions; and (iv) that at the same time that homophobia is declining in one part of the world, it can dramatically intensify elsewhere. Most importantly, these cases offer evidence that homophobia is socially constructed and that levels and configurations of homophobia can vary widely. 
In their recent paper McCormack and Anderson (2014) summarize their research into situations that exhibit declining homophobia in key settings in North America and the United Kingdom. They raise the possibility that their concept homohysteria might serve as a useful model for explaining this decline. In order to evaluate their claims concerning changing patterns of homophobia, this paper will first revisit current definitions of homophobia and interrogate current explanations for why it exists. Being clear about what homophobia is will lay the groundwork for understanding how it can change. This paper will then propose a set of criteria that need to be met in order for a model that explains the ebb and flow of homophobia to be considered robust and meaningful. Finally I will outline an alternative model which accounts for McCormack and Anderson's findings, but which approaches them from a different perspective. This gender taboo theory of homophobia appears to account both for why homophobia exists and, importantly for the current paper, how it can escalate and decline.

\section{Nailing down homophobia}

Before we can do an adequate explication of the ebb and flow of homophobia, it is necessary to establish some clarity around what homophobia actually is. This clarity is important because it will form the basis for the arguments advanced in this paper, and also because derivative concepts such as homohysteria (Anderson, 2009) are constructed on the edifice of homophobia, and persisting ambiguity would undermine the entire enterprise of understanding homophobia and its consequences better. Further, for the sake of precision and to avoid conflating important, but distinct, phenomena, this paper will focus on homophobia directed at males.

It often seems that homophobia is a hall of mirrors, largely because every time you look at it you are confronted with so many confusing binaries. Certainly, the term homophobia is notorious for its definitional problems and theoretical uncertainty (see the discussion by McCormack \& Anderson, 2014). It is redundant here to recount the story of the invention of the term by Weinberg in 1972, but it is important to note that since the term homophobia was coined, it has undergone important shifts in meaning and there has been a steady procession of alternative terms and associated theories proposed (Anderson, 2009; Fyfe, 1983; Haaga, 1991; Hansen, 1982; Herek, 1984; McCormack, 2012; Neisen, 1990; Plummer, 2007).

Perhaps the best known of these is heterosexism, which, as useful as it might be, fails to capture the significance that homophobia conveys (for a definition of heterosexism and further discussion see, Neisen, 1990). For example, reference to a homophobic murder seems disturbingly meaningful, whereas I am yet to hear anybody describe a murder as heterosexist. In this context heterosexism seems too bland, lacking any tangible connotations of the passion associated with homophobia (the malevolence, pathology, danger) and sounds more like a compromise term invented by an administrator. Herein lies an important point, any satisfactory theoretical framework that aims to account for homophobia and its consequences has to capture the depth of feeling, the cathexis, and the near global preoccupation with homophobia that modernity has witnessed (for evidence of this cathexis and global preoccupation, see the diverse accounts in Tin, 2008). The depth and extent of this social investment in homophobia, both for and against, seems to indicate that there is much more at stake than merely a discomfort with a small minority of stereotypically effeminate men, as important as they are to you and me.

The most usual understanding of homophobia, by academics and social commentators alike, is that it represents a prejudice against homosexuals. This definition is reflected in 
authoritative sources such as the Shorter Oxford Dictionary, which defines homophobia as the 'fear or hatred of homosexuals and homosexuality' (Trumble, 2007). The clear implication of this prevalent use of the term therefore, is that the primary target of homophobia is homosexuality. Yet, there is considerable evidence that the dictionary definition and corresponding academic use of the term do not reflect the meanings conveyed by homophobic epithets in everyday life (for example, see Athenases \& Comar, 2008 in student speech in a Californian middle school; Fair, 2011 among high school wrestlers in California and Massachusetts; Plummer, 1999, 2001a, 2001b among young Australian men). This gap between formal definitions and everyday use is an interesting and, as it turns out, an important piece of the puzzle and suggests that the definition of homophobia, for the time being, should remain an unsettled question. In order to manage these definitional problems without derailing the important enterprise of theorizing homophobia better, I took a strategic decision in my research not to seek alternative terms, which it seemed to me would only ever gain traction in light of a satisfactory underlying theoretical framework, which was still far from worked out. Instead, despite its definitional shortcomings, it seemed strategic to accept the most current term, homophobia, as a placeholder, to research the complex meanings associated with it and related terms, to unpack those meanings and to work to reconcile formal definitions with the lived realities of everyday homophobia.

\section{Insights from Australian research}

One way to shed light on the social construction of homophobic meanings in the everyday life of young men is to interview them about their experiences while growing up and to map those experiences chronologically in order to understand the processes that underwrite how those meanings are acquired. This was done by the present author who worked with young Australian men using a modified grounded theory approach to collect developmental accounts of their emerging understandings of gender and homophobia (Plummer, 1999). For the purposes of the research, the participants also functioned as lay field observers and provided accounts of complex social systems and processes, including schools, families, peer groups, sport and street life. For further details about the approach and methods used, see Plummer (1999, 2001a).

A number of features emerged from this research that offer powerful insights into how homophobia comes to be understood by these young men. First, it was notable that boys are typically exposed to and start using homophobic words such as poofter and faggot at a very young age, usually well before sexual maturation. When asked what these terms were supposed to mean at that early age, the standard response was that they were meaningless. However, further questioning revealed that this was not the case. When asked whether words like poofter or faggot were ever used against girls, the answer was invariably in the negative and that such a usage simply wouldn't make sense (Plummer, 1999, p. 42). This answer is revealing as it demonstrates that these words are both gendered and they do in some way make sense from their very first appearance - albeit, perhaps not in the way that the adult world understands them. When asked whether these terms were ever used in a positive way or to complement someone, the answer was also invariably to the negative, although they sometimes could be used as a joke. Indeed, when asked to list and rank the swear words used in the school ground, homophobic epithets were by far the ones that boys wanted to avoid being labelled with more than any other (Plummer 1999, p. 67).

When asked what people or characteristics triggered these words (on the assumption that these would reflect their meaning), a complex array of characteristics, appearances and behaviors were listed. Yet, despite being wide ranging, it is important to note that the 
multitude of features attributed to homophobic words were not a random jumble of abuse, on the contrary, their use was very consistent. Characteristics associated with homophobic meanings and which triggered homophobic outbursts typically fell into the following broad categories (based on Plummer, 1999, 2001a, 2001b, 2005):

- Physical immaturity \& lacking in physical development. Boys who were small, pale, weak, under-developed or late developers were more prone to being targeted with homophobic terms; conversely boys who were well developed, physically assertive and who valorised male physicality were less so.

- Unassertive character \& lacking in authority. Boys who were timid, submissive, obedient, lacked courage, eschewed risk-taking, respected rules, and/or who erred on the side of safety were more vulnerable to being targeted with homophobia; conversely boys who were charismatic, assertive, dominant, courageous, risk-takers were less vulnerable.

- Questionable allegiances within the peer group. Boys who were loners, chose homework over play, avoided team sports, or betrayed peer group solidarity were more prone to being targeted with homophobia; conversely boys who were team-players and preferred outdoors activities were less prone.

- Conformity to authorities external to the peer group. Boys who conformed to parental expectations, respected the law and tried to please teachers at the expense of peer group loyalty were more likely to be targeted with homophobia; whereas boys who showed loyalty and solidarity with the male peer group culture were less likely.

- Gender non-conformity in appearance or demeanour. Boys whose style of dress, speech, gestures, gait, deportment, vigour and physicality did not meet gender expectations were vulnerable to being targeted with homophobia; conversely boys who dressed in sporting clothes, wore sports brand names and donned clothing that pushed the envelope of school dress-codes were less vulnerable.

- Sexual difference. Boys who were not overtly heterosexual; who offered no tangible evidence of heterosexual interest; or who were assumed to be gay were prone to homophobia; conversely boys who showed signs of being aggressively heterosexual were less prone.

Perhaps reassuringly, all participants were in agreement that poofter and faggot are indeed homophobic terms and the list of meanings associated with these homophobic epithets did indeed include taboos about sexual orientation, but that these were among a long list of other meanings - and were often not the most important or relevant ones, depending on the circumstances. Moreover, when examining the sequential attribution of meanings to homophobic terms, the anti-gay connotations were generally layered on top of all the other meanings at a later stage as the child moved closer to high school and puberty (a process I refer to elsewhere as onion skinning (Plummer, 1999, p. 44)). It is also worth noting that homophobic words were rarely used in the light of knowledge about what the target boy did in bed, indeed the epithets were in common circulation among boys before sexual maturation and the most frequent target was not, and may well never be gay. Notably, boys who did have emerging gay identities always did so after first having been indoctrinated with homophobic taboos.

\section{Unpacking the evidence}

So what can be made of the Australian data on the developmental construction of meaning invested in homophobic epithets, and therefore I would argue the construction of homophobia in society at large? 
First, homophobic epithets like poofter and faggot are revealed to have multiple, complex layers of meaning progressively attributed to them as young people mature. The developmental accounts from the research show that these various meanings are typically added into homophobic terms sequentially: starting with taboos about being a baby or a girl, adding taboos against breaching boys' peer group solidarity, and ultimately to incorporating anti-gay references.

Second, the earliest meanings attributed to homophobic epithets don't simply vanish and become replaced by new ones. To the contrary, the earlier significances persist even as new meanings were layered over them (onion skinning). This developmental ordering was found to be broadly consistent across the diverse range of accounts in the research and this raises the possibility that these accounts are, in fact, descriptions of the progressive social construction of homophobic understandings - constructions in which later meanings (such as anti-gay taboos) are founded on, and grounded in the meanings that preceded them (such as taboos about men showing signs of femininity). Thus, words like poofter and faggot can simultaneously convey composite negative connotations about being a baby, sissy, weakling, loser and a homosexual.

Third, the evidence reveals that, from their earliest introduction, homophobic epithets like poofter and faggot do not make sense when applied to girls. In other words, these homophobic terms start life as gendered words prior to them acquiring explicit sexual connotations. Significantly, as I indicated above, these earlier meanings do not simply vanish when new meanings arise; they persist and underwrite subsequent meanings. This sequence of events - of anti-gay connotations being built on gendered foundations - raises the prospect that this is an important cultural mechanism for welding gender and sexual taboos together and for explaining how homophobic knowledge becomes socially constructed, at least in the minds of these young Australian men.

Fourth, there remains the key question as to how coherence is attained across such a complex, multifaceted, progressively-constructed array of meanings. In the case of the Australian data, overall coherence is arguably made possible because all of the meanings attributed to homophobic epithets share the common ground of being taboos about what real men should not do or be. In effect, by tracing the progressive attribution of meaning to terms like poofter and faggot it was possible to observe the progressive multilayered construction of the male other (a composite faggot). This construction continued up to, and ultimately included, the adult male other's non-heterosexual sexual difference, almost as a final touch (Plummer 2001a).

The above findings offer an attractive model for explaining contemporary homophobia for a number of reasons, not least because they provide an opportunity to resolve some of the paradoxes, contradictions and lack of clarity that have plagued our understanding of homophobia until now. The grounding of homophobia first and foremost in complex gender taboos offers an explanation for why definitions, meanings and theory relating to homophobia seem to have been so uncertain for so long, particularly when the focus has been on sexuality at the expense of not fully unpacking the other meanings inherent in homophobic discourses (Falomir-Pichastor \& Mugny, 2009; Froyum, 2007; Kimmel, 1994, pp.119-141; McCormack, 2012; O'Conor; 1995; Pascoe, 2007). The layering of significance, including the penultimate incorporation of anti-homosexual meanings, confirms that homophobia is indeed a prejudice about sexual orientation, but not solely or perhaps even principally so. Yet even when it comes to the anti-homosexual aspects of homophobic terms, there is no need to 
look far to find gender lurking in plain sight: the distinguishing feature of homosexuality is not sexual practice, which is extremely diverse, but, by definition, that the participants in homosexual practice are of the same sex (gender). Thus gender transgression, rather than sexual practice per se, is the necessary pre-requisite for homophobia even in situations where homophobia is indeed directly triggered by homosexuality.

\section{Why so cathected?}

It has always seemed paradoxical to me that societies (including largely secular ones) invest so much attention and energy into homophobia while the principal target apparently consists of a small minority of (stereotypically effeminate) men who do not appear to pose any obvious threat to anyone (for the extent of the global investment in homophobia, see Tin, 2008; for a range of studies on the prevalence of homosexuality, see the Kinsey Institute at http://www.kinseyinstitute.org/resources/bib-homoprev.html). However, when we take the above developmental evidence into account - that the foundations of homophobic meanings rest on gender taboos, especially masculine taboos and male social power - this deep cathexis makes much more sense and explains why homosexuality has been such a hot button issue for so long (Plummer, 2005, pp. 218-232).

So what is homophobia actually doing? Elsewhere I have argued that contemporary homophobia plays an important role in policing manhood (Plummer, 2001b). It does this by drawing attention to gender taboos and thereby defines the boundaries of acceptable masculinity, including the sexual boundaries. Transgressing those boundaries entails encroaching the domain of the male other and threatens to align the transgressor with the sibilant, mincing, pale, effete, soft, pansy, sissy, passive, homosexual, taboo male other, which you may recognize to be a stereotypical composite of all of the meanings that the child learned to associate with words like poofter and faggot in the school ground. In a nutshell then, the evidence suggests that homophobia among men is an overt manifestation of a subterranean web of masculine taboos whose main effect is to entrench orthodox masculinity and thereby to maintain the gender order.

But for homophobia to police masculinity effectively, it must have teeth. This is where the depth of feeling comes in: the passion, and the murderous fury directed against those who break ranks with dominant masculinity (Berrill, 1992; Herek \& Berrill, 1992). Indeed, modern homophobia can be understood as a system of punishment for crimes against manhood, and sometimes that punishment entails murder (Plummer, 2005, pp. 218-232). In this regard, homophobia shares many similarities with misogyny, but with a key distinction that misogyny demarcates the inter-gender divide between men and women, whereas homophobia demarcates an intra-gender divide between real men and suspect men.

This analysis raises a further point concerning the role of homophobia in policing gender roles. The taboos and stigma associated with homophobic terms leads boys to quickly learn to avoid any association with these labels from a young age. The depth of homophobic indoctrination that occurs in school grounds on a daily basis results in most boys ranking homophobic epithets to be among the worst labels with which to be targeted. This indoctrination leads to an evasive fear of homophobia, or homophobia-phobia as I call it (Plummer, 1999, p. 65), an aversion which I argue is actually much closer to a true phobia than homophobia is itself.

\section{Shifting gender relations and the passage to manhood: perspectives from the Caribbean Masculinities Project}


Subsequent to the Australian research outlined above, the present author undertook research in several Anglophone Caribbean countries using a similar approach (conducted in Anguilla, Grenada, Guyana, Jamaica, St Kitts \& Nevis, St Lucia, St Vincent \& the Grenadines, and Trinidad \& Tobago; for full details of the methods see Plummer (2013)). This latter research, known as the Caribbean Masculinities Project, was instituted in response to three key regional concerns: first, the prevalence of HIV in parts of the Caribbean is among the highest in the world (UNAIDS, 2013); second, growing concerns about rising levels of homophobia in the region, and third, there was a growing body of evidence that boy's participation in education in the Anglophone Caribbean was undergoing a pronounced, sustained decline (for detailed analysis, see Reddock, 2004, p. xv; Figueroa 2004, pp. 141-143; Plummer 2013).

All of these issues raised questions about the nature and interplay of prevalent masculinities. As a result, the Caribbean Masculinities Project primarily set out to explore the question of changing masculinities and shifting gender relations, particularly in relation to risk-taking (Plummer, 2009, 2013; Plummer \& Geofroy, 2010). Importantly, the Caribbean masculinities research took place against a backdrop of significant improvements in recent decades in the roles and status of Caribbean women, although like everywhere there is still a long way to go for equality (Reddock, 2004, 2009). Interestingly, despite very different cultural, racial and geographic contexts, the research revealed several key parallels to those reported in the Australian research described earlier, especially in (i) the influence exerted by masculine taboos in shaping gender understandings during the passage from childhood to manhood; (ii) the ways that complex homophobic meanings become constructed in the minds of young men; and (ii) the relationships between gender taboos and the meanings invoked by homophobic epithets (see Plummer, 2009, 2013; Plummer \& Geofroy, 2010).

The Caribbean research highlighted the importance of gender binaries for the way young men come to understand and negotiate gender roles and conventions during the passage from childhood to manhood (Plummer, 2009, 2013). These binaries appeared to be very important for the way that young men come to terms with gender even though they may not turn out to be nearly so clear-cut in everyday life. But the significant point for the present discussion, that was central for the Caribbean research, is that gender binaries are mutually exclusive (Plummer, 2013). That is to say the same qualities that conceptually serve to define femininity cannot simultaneously serve to define masculinity and vice versa, at least not in any conventional sense. The implications of these findings are far-reaching - this mutuality ties the defining qualities of masculinity and femininity together and therefore, any shifts in the status, roles and defining qualities of womanhood will necessarily entail changes in the roles, status and defining qualities of manhood. Nowhere is this mutuality more important than during the developmental passage from childhood to adulthood when adult gendered identities are consolidating and being road-tested. These shifts do not necessarily have to entail the feminization of traditional male roles, all that is required is equality. This is because key areas of life that were traditionally available for boys to hone their masculine credentials during the transition to adulthood and to prove that they are men (such as education, literacy and intellectual prowess), while still valuable for many other reasons, are increasingly unlikely to be viewed as useful or legitimate vehicles through which boys can establish their masculine status on the modern day journey to manhood. In retrospect, a similar mutual exclusivity was also seen in the Australian data presented earlier. Indeed, both the Australian and Caribbean data revealed that boys who make an effort to do well in class, to please the teacher, to get good marks and to use correct grammar are increasingly the subject of homophobic harassment (Australian data see Plummer 1999, 2001a; Caribbean data see Plummer, McLean \& Simpson 2008). However, possessing and projecting an acceptable 
adult gender identity remains as important as ever, and with growing social equality the quest for a gender identity sees boys relying increasingly on physical biological differences such as musculature, strength, body hair, penis size and on what can be done with that physicality: display it in sports; decorate it with athletic brand names and bling; broadcast it through sexual conquests; and impose it by force, including through aggression and violence (Mora, 2013; Plummer \& Geofroy, 2010). Elsewhere, I have referred to these shifts in contemporary male gender arrangements (away from intellectual prowess and towards physicality) as the retreat to the body and the (re)emergence of hard masculinity (Plummer, 2013).

\section{Theorizing the ebb and flow of homophobia}

Finding that some parts of the world, (such as areas of North America and the United Kingdom reported by McCormack and Anderson (2010, 2014)) are experiencing declines in homophobia is both interesting and important, not least because it raises the possibility that life might eventually be better for a large number of people. However, finding that homophobia can vary may not be as illuminating as it first appears, given the complex multifaceted significance associated with homophobia outlined earlier. In order to make use of these observations, researchers will need to ask: What exactly is it that is declining or intensifying? What wider social significance does the shift indicate? Why has the shift occurred at this point in time? What are the necessary pre-conditions for the shift to occur? How permanent will it be?

It is clear from the earlier discussion that homophobia is multidimensional, and so too therefore are the many meanings associated with homophobia, which would presumably shift as homophobia itself ebbs and flows. Arguably therefore, based on the preceding analysis, for a theory to provide a satisfactory explanation of the shifting intensities of homophobia a number of criteria would need to be satisfied, including:

- Elucidate the mechanism(s) that produce coherence between various forms of homophobia(s) and the many meanings invoked by homophobic terms

- Address gender, especially gender taboos and shifting gender arrangements (which in the present paper is a key candidate for supplying the coherence mentioned in the previous point)

- Be reconciled and in accord with the experiences and praxis of homophobia(s) in everyday life

- Be able to explain shifting intensities and degrees of cathexis, including the almost obsessive pre-occupation that many societies invest into homophobia(s), even now

- Be able to account for both reductions and escalations of homophobia, beyond simply describing them

- Allow for the possibility that homophobic détente may well be tenuous, short-lived and susceptible to dramatic reversals

- Accommodate social and cultural scenarios outside of the usual secure, middle-class developed-world perspectives

Earlier a case was made that contemporary male homophobic meanings are grounded in taboos about masculinity. It was also argued that gender is conceptualized in mutually exclusive ways, particularly when gendered identities are being consolidated during the passage to manhood. The correlate of these findings is that any shift in gender relations may well also be reflected in movements in the intensity and social significance associated with homophobia, particularly when power, gender relations, and gender taboos are challenged and tensions emerge. It should be noted, however, that this argument should not be taken as an attempt to write sexuality out of the story. The aim is to reposition sexuality to where it 
seems to make the most sense. Sexuality is still deeply implicated, not least because it concerns the interplay of gender roles.

In their recent paper, McCormack and Anderson (2014) theorize three principal patterns of homophobia, which, in essence, are distinguished by the absence, presence or decline in homohysteria. However, the data presented in the present paper suggests a somewhat different interpretation. Using a gender lens to unpack homophobia leads to the proposition that changing gender relations might substantially underwrite the ebb and flow of homophobia, and thereby precipitate (or ease) social anxiety, gender-based moral panics and homohysteria. I now want to postulate some mechanisms to explain this alternative position.

Shifting gender arrangements, such as greater equality for women necessarily entails shifts for men too. Moreover, shifts in gender arrangements between men and women will also entail shifts of the intra-gender boundary between real men and the male other. Earlier we saw that this intra-gender boundary is policed by homophobia, at least in the Anglophone contexts reported here. It would not be surprising, therefore, if emerging gender tensions and shifting gender relations were to impact on patterns of homophobia. Of course, gender is a key domain for the operation of social power, so these shifts would not necessarily be accepted passively. In the Caribbean data outlined above and reported in detail elsewhere (Plummer, 2013), it was arguably the case that shifting gender relations resulted in (i) a retreat to the physical male body because it offered a more secure reference point for differentiating gender identity, (ii) the re-emergence of hard masculinity as a performative physical aspect of the passage to manhood, and (iii) the rekindling of homophobia to target males who do not embody hard, physical masculinity, notably those who are studious, gentle, soft, effete, effeminate and, on some occasions, gay.

In the case of research by McCormack and Anderson (Anderson, 2005, 2008, 2011a, 2011b; Anderson, Adams \& Rivers 2012; McCormack \& Anderson, 2010, 2014) into situations that demonstrate declining homophobia in the UK and the United States, the authors appear to be describing an alternative pattern of responding to shifting gender arrangements, where middle-class masculinity is shifting to accommodate these changes and to be redefined in more egalitarian terms. This shift includes the de-conflation of homosexuality from gender stereotypes with a consequent reduction in homophobia. In their paper (2014), McCormack and Anderson briefly also make reference to homophobia in Iran which they argue has low levels of homohysteria despite there being harsh penalties for homosexuality (see also Tin, 2008, p. 11; Schmitt \& Sofer, 1992; Shakhsari, 2012). My reading of this case is that in very conservative regimes, especially religious ones, the prospect of shifting gender arrangements is simply met with official rejection, for which enforcement and transgression can entail harsh penalties. These measures include surgical correction of gender incongruity in order to transform potential homosexual scenarios into a configuration that appears to preserve heterosexual gender relations and the death penalty for homosexual practice where gender relations are transgressed (Najmabadi, 2011).

To summarize, as the result of unpacking the evidence that homophobia is underwritten by gender taboos and that shifting levels of homophobia are related to shifting gender arrangements, there would appear to be at least three broad patterns of response to the prospect that gender conventions might change:

- Rejection is characterized by a steadfast refusal to countenance any deviation from orthodox gender arrangements. The consequences for men (and women) who transgress 
gender codes can be uncompromising, including in some places, the death penalty for homosexuality.

- Reaction is characterized by a reactionary response to shifting gender conventions. In the Caribbean research outlined above, this reaction was characterized by a retreat to the safe ground of the physical male body, valorization of hard masculinity, and rekindling of homophobia against non-conforming males (only some of whom are ever destined to be gay).

- Accommodation occurs in circumstances where the status and roles of both men and women are shifting and there is sufficient social space, stability, security and personal resources for men to accommodate those changes and to rework a more inclusive masculinity (Anderson, 2009). Such changes can entail a de-conflation that unlinks gender taboos from homosexual stereotypes and therefore also a separation of masculinity from obligatory homophobia.

In my reading, McCormack and Anderson (2014) would locate homohysteria in the reaction category above, with a key distinction that the hysteria in their model is the result of a pervasive fear that homosexual men are commonplace despite them being considered socially unacceptable. In the gender taboo model of homophobia (proposed here), the reaction scenario consists of homophobia against men who are do not conform to gender expectations (including, but not limited to, sexual transgression) and who fail to project sufficiently hard, physical masculinity. The other distinction is that in the taboo model there is a continuum: from highly taboo with uncompromising, officially-sanctioned homophobia (rejection); through to informal homophobia, which never-the-less can be just as deadly (reaction); through to low levels of anti-gay taboo and the dissipation of overt homophobia (accommodation), although it is unclear how deep this easing goes, how widespread it will become and how long it will last.

At this point it is opportune to clarify an underlying assumption of this paper: that homophobia is socially constructed. Clearly in this forum I run the risk of preaching to the converted, but there are a few points that will help to round out the case. The description of the progressive layering of meanings into homophobic epithets and great variations in the ebb and flow of homophobia, including the capacity to suspend homophobia on a temporary basis and to accept homointimacy in a range of cultural settings without provoking homophobia, are evidence that support the conclusion that homophobia is not hard-wired. Indeed the data presented in the first section demonstrates how homophobia is learned and that it can be unlearned (McCann, Minichiello, Plummer, 2009). This being the case, the constructed nature of homophobic meanings provides for the possibility of historical and cultural specificities, individual agency and indeed very real shifts in homophobia. The finding that homophobia is socially constructed is good news, because it suggests, in turn, that it might be possible to construct it right out of existence again.

The proposition that homophobia is a constructed multilayered manifestation of gender taboos also raises another possibility: that homosexuality can be delinked from masculine taboos as a consequence of masculinity being remodeled as gender arrangements shift. This reconstructability of gender would also mean that homophobia need no longer be equated with masculinity (for a discussion of homophobic masculinity, see Kimmel 1994). I would argue that this delinking is what McCormack and Anderson and others are observing in their work (Adams, 2011; Anderson, 2005, 2008, 2009, 2011a, 2011b; Anderson, Adams \& Rivers, 2012; Horn, 2007; McCormack \& Anderson, 2010, 2014; Pascoe, 2007). Of particular interest - because having a gender identity remains as essential as ever - is who or 
what the defining other of the new man will be? Perhaps the man who has failed to make the transition to the new man? I am also optimistic that with the alleviation of homophobia, misogyny will also decline given my arguments about the relationship between homophobia and gender taboos. But we should not forget that in many parts of the world, homophobia seems to be on the rise and this must be a cause for concern for anyone interested in gender equity.

\section{Where does homohysteria fit and what does it tell us?}

McCormack and Anderson (2014) have made some significant observations about declining levels of homophobia in situations where the presence of homophobia was previously well known, namely schools, colleges, sporting teams and all male settings in developed Anglophone countries. These observations constitute important sentinel findings in the sense that they raise the prospect that homophobia can shift, and therefore it might eventually be possible for improvements to gain momentum and for homophobia and its attendant antisocial consequences to be overcome completely. In an attempt to explain declining homophobia, Anderson (2009) introduced the term homohysteria, which I understand to be a reference to heightened anxieties triggered by an awareness of the existence of homosexuals in a culture that considers homosexuality to be socially unacceptable. However, the introduction of the term homohysteria raises a number of fundamental questions, not least of which is to what extent it helps to explain the ebb and flow of homophobia?

In unpacking these issues, I will first try to dispense with the etymological problems inherent in the term homohysteria. It is interesting that homohysteria has a very similar structure to homophobia, and this might be its Achilles heel. Because of this similarity, the term appears to be susceptible to similar critiques to those that have been made of homophobia already. For example, in both cases, the second phobia/hysteria element is borrowed from the psychological literature and in a similar way that homophobia is no longer considered to be a true phobia, homohysteria will never be considered to be a true hysteria (Haaga, 1991; Plummer 1999, pp. 4-5). Moreover, both homophobia and homohysteria, describe collective socio-cultural phenomena and the appropriateness of using a term that was previously used to describe individual psychopathological syndromes is open to question.

The second etymological problem concerns the historical origins of the term hysteria. Gender researchers are well aware that hysteria has been widely critiqued as an example of pseudoscientific misogyny that dates back as far as the early 1600s (see Meek, 2013; Tasca, Rapetti, Carta \& Fadda, 2012; Trumble, 2007). In the case of homohysteria, the deployment of the term seems to have reversed the target, in that, like homophobia, the term pathologizes specific forms of social reaction against homosexuality rather than labeling homosexual men and women as hysterical themselves. At this point, it is unclear whether this reversal will be sufficient to satisfy the critics who may well question the wisdom of using a term with such deep historical links to misogyny.

Now let us turn from etymology to the meaning the authors intended the term to have. According to the arguments advanced by McCormack and Anderson (2014), homohysteria describes certain reactions by people in homophobic cultural settings when confronted with the realization that homosexuals are invariably also present in those settings. These reactions might best be thought of as heightened states of personal anxiety and/or a growing sense of collective moral panic. The evidence presented is convincing, but it does raise the question as to whether the term homohysteria makes a necessary distinction or that what is actually being described is a heightened or variant expression of homophobia? In other words, what does 
homohysteria add, that homophobia (and the admittedly inelegant term, homophobia-phobia) does not already say?

Beyond using the term to describe an hysterical reaction to the realization that homosexuality is ubiquitous despite it being unacceptable, it is important to ask, will homohysteria stand the test of time as the basis of an explanatory theory for the ebb and flow of homophobia? In my assessment, there is a long way to go. First the term has to survive its etymology. Second, researchers will need to be convinced that it contributes something to theory beyond what is already available using the existing lexicon. At present, I see homohysteria in the same boat as its famous older cousin, homophobia, which has spent more than forty years as an extremely useful misnomer on a mission to find a better theory.

\section{Conclusion}

In the quest to develop a more adequate theoretical basis for explaining homophobia, a series of criteria are proposed that an emergent theory would need to satisfy in order to be considered robust. These criteria are: (i) the model explains the coherence between the multiple diverse meanings associated with homophobic terms (ii) there is correspondence between the theory and everyday homophobic experiences and praxis; (iii) the model addresses gender, gender taboos and gender relationships; (iv) the model explains the intense cathexis that many societies invest in homophobia; (v) the model accounts for escalations and reductions in homophobia; (vi) the model allows for the possibility that improvements might only be temporary; and (vii) ideally, the model should accommodate scenarios beyond the security, stability and cultural context of the developed world.

In a series of studies over a number of years, Anderson, McCormack and others have documented a number of circumstances where male homophobia is low and/or in decline (Anderson, 2005, 2008, 2009, 2011a, 2011b; Anderson, Adams \& Rivers, 2012; McCormack \& Anderson, 2010, 2014). Over a similar period, my own work has examined settings where male homophobia is historically high and/or escalating (Plummer, 1999, 2005, 2009, 2013; Plummer \& Geofroy, 2010). Using a gender lens to interpret these divergent studies it is possible to propose a model that satisfies the above criteria and explains both the rise and fall of homophobia. Gender taboo theory provides a coherent explanation for the existence of homophobia and for what drives it up and down. It does this by seeing male homophobia as an overt expression of a complex system of masculine taboos in which homophobia has come to play a primary role in defining and enforcing those gender taboos and in policing and punishing gender transgressions. By identifying links between the shifting levels of homophobia and shifting gender relations, the gender taboo theory also offers a plausible explanation for how and why homophobia intensifies and subsides. What emerges are three broad patterns of homophobia that, in essence are determined by how receptive host cultures are to gender transformations and under what circumstances, and how they respond to gender transgression. These patterns are: (i) Rejection: a steadfast refusal to accommodate gender role change and harsh responses against transgression; (ii) Reaction: a reactionary response against gender role change accompanied by a retreat to more secure, fundamental versions of masculinity; and (iii) Accommodation: gender role change is accommodated, which is perhaps most likely in stable, economically secure social settings where there is sufficient latitude for men to rework their masculinity.

It hardly needs to be said that gaining a better understanding homophobia is a critical issue for the wellbeing of gay, lesbian, bisexual and transgender people. In that regard alone, knowing what factors drive the ebb and flow of homophobia potentially paves the way for 
unprecedented improvements in the lives of people who are affected by this serious antisocial problem. Moreover, this paper also argues that researching the escalation and decline of homophobia is vital because homophobia plays such a central role in the apparatus that polices, enforces and sustains gender inequities in society as a whole. While homophobia has traditionally been understood through the lens of sexuality, there is a strong case for researching homophobia though the lens of gender taboos. It is through this lens that the full significance of homophobia for gender theory and practice becomes apparent and a coherent explanation for homophobia emerges.

\section{References}

Adams, A. (2011). 'Josh wears pink cleats': inclusive masculinity on the soccer field. Journal of Homosexuality, 58, 579-596. doi: 10.1080/00918369.2011.563654

Anderson, E. (2005). Orthodox and inclusive masculinity: competing masculinities among heterosexual men in a feminized terrain. Sociological Perspectives, 84, 337-355. doi: 10.1525/sop.2005.48.3.337

Anderson, E. (2008). Inclusive masculinity in a fraternal setting. Men and masculinities, 10, 604-620. doi: 10.1177/1097184X06291907

Anderson, E. (2009). Inclusive masculinity: The changing nature of masculinities. London: Routledge.

Anderson, E. (2011a). Masculinities and sexualities in sport and physical cultures: three decades of evolving research. Journal of Homosexuality, 58, 565-578. doi: $10.1080 / 00918369.2011 .563652$

Anderson, E. (2011b). Inclusive masculinities of university soccer players in the American mid-west. Gender and Education, 23, 729-744. doi: 0.1080/09540253.2010.528377

Anderson, E., Adams, A., \& Rivers, I. (2012). 'I kiss them because I love them': the emergence of heterosexual men kissing in British institutes of education. Archives of Sexual Behaviour, 41, 421-430. doi: 10.1007/s10508.010.9678.0

Athenases S.Z., \& Comar, T.A. (2008). The performance of homophobia in early adolescents' everyday speech. Journal of LGBT Youth, 5(2), 9-32. doi: $10.1080 / 19361650802092366$

Awondo, P., Geschiere, P., \& Reid, G. (2012). Homophobic Africa? Toward a more nuanced view. African Studies Review, 55(3), 145-168. doi: 10.1017/S0002020600007241

Bakare-Yusuf, B. (2006). Clashing interpretations in Jamaican dancehall culture. Small Axe, 21, 161-173. doi: 10.1215/-10-3-161

Berrill, K.T. (1992). Antigay violence and victimisation in the United States: An overview, in G.M. Herek \& K.T. Berrill KT (Eds.), Hate Crimes: confronting violence against lesbians and gay men (pp. 19-45). London: Sage.

Boyd, L. (2013). The problem with freedom: homosexuality and human rights in Uganda. Anthropological Quarterly, 86, 697-724. doi: 10.1353/anq.2013.0034. 
Fair, B. (2011). Constructing masculinity through penetration discourse: the intersection of misogyny and homophobia in high school wrestling. Men and Masculinities, 14, 491-504. doi: $10.1177 / 1097184 X 103755936$

Falomir-Pichastor, J.M., \& Mugny, G. (2009). 'I'm not gay... I'm a real man!' heterosexual men's gender self-esteem and sexual prejudice. Personality \& Social Psychology Bulletin, 35, 1233-1243. doi: 10.1177/0146167209338072

Figueroa, M. (2004). Male privileging and male academic under- performance in Jamaica. In R. E. Reddock (Ed.), Interrogating Caribbean masculinities (pp. 137-166). Mona, Jamaica: University of the West Indies Press.

Froyum, C.M. (2007). 'At least I'm not gay': heterosexual identity making among poor black teens. Sexualities, 10, 603-622. doi: 10.1177/1363460707083171

Fyfe, B. (1983). 'Homophobia' or homosexual bias reconsidered. Archives of Sexual Behaviour, 12, 549-554. doi: 10.1007/BF01542216

Gay Rights: Legalised Homophobia. (2013). Africa Research Bulletin: Political, Social and Cultural Series, 50(6): 19760A-19760C. doi: 10.1111/j.1467-825X.2013.05196.x

Grau, G. (1993). Hidden Holocaust? London: Cassell.

Haaga, D.A.F. (1991). Homophobia? Journal of Social Behaviour and Personality, 6, 171174.

Hansen, G.L. (1982). Androgyny, sex role orientation and homosexism. Journal of Psychology, 112, 39-45. doi: 10.1080/00223980.1982.9923532

Herdt, G.H. (1993). Ritualised homosexual behaviour in the male cults of Melanesia, 18621983. In G. Herdt (Ed.), Ritualised homosexuality in Melanesia (pp. 1-82). Berkeley, CA: University of California Press.

Herek, G.M. (1984). Beyond homophobia: a social psychological perspective on attitudes towards lesbians and gay men. Journal of Homosexuality, 10(1/2), 1-21. doi: 10.1300/J082v10n01_01

Herek, G.M., \& Berrill, K.T. (1992). Hate Crimes: Confronting Violence against Lesbians and Gay Men. London: Sage.

Horn, S.S. (2007). Adolescents' acceptance of same-sex peers based on sexual orientation and gender expression. Journal of Youth and Adolescence, 36, 363-371. doi: 10.1007/s10964-0069111-0

Human Rights/Homophobia: Uganda. (2011). Africa Research Bulletin: Political, Social and Cultural Series, 48, 18711C-18713B. doi: 10.1111/j.1467-825X.2011.03693.x

Human rights: Nigeria's Controversial Bill. (2014). Africa Research Bulletin: Political, Social and Cultural Series, 50, 19976A-19977B. doi: 10.1111/j.1467-825X.2014.05498.x 
Human Rights: Uganda passes anti-gay law. (2014). Africa Research Bulletin: Political, Social and Cultural Series, 50, 19976B-19977C. doi: 10.1111/j.1467-825X.2014.05498.x

Ireland, P.R. (2013). A macro-level analysis of the scope, causes and consequences of homophobia in Africa. African Studies Review, 56, 48-66. doi: 10.1017/asr.2013.41

Jonas, O. (2013). The quest for homosexual freedom in Africa: A survey of selected continental practices and experiences. International Journal of Discrimination and the Law, 12, 221-242. doi: 10.1177/1358229112471477.

Kimmel, M.S. (1994). Masculinity as homophobia. In H. Brod \& M. Kaufman (Eds.), Theorizing masculinities (pp. 119-141). London: Sage.

McCann, P., Minichiello, V., \& Plummer, D. (2009). Is homophobia inevitable? Evidence that explores the constructed nature of homophobia, and the techniques through which men unlearn it. Journal of Sociology, 45, 201-220. doi: 10.1177/1440783309103347

McCormack, M. (2012). The declining significance of homophobia: How teenage boys are redefining masculinity and homophobia. New York: Oxford University Press.

McCormack, M., \& Anderson, E. (2010). 'It's just not acceptable any more': the erosion of homophobia and the softening of masculinity at an English sixth form. Sociology, 44, 843859. doi: $10.1177 / 0038038510375734$

McCormack, M., \& Anderson, E. (2014). The influence of declining homophobia on men's gender in the United States: An argument for the study of homohysteria. Sex Roles, this issue. doi: 10.1007/s11199-014-0358-8

Meek, H. (2013). Medical Men, Women of Letters, and Treatments for Eighteenth-Century Hysteria. Journal of Medical Humanities, 34, 1-14. doi: 10.1007/s10912-012-9194-4

Mora, R. (2013). 'Dicks are for chicks': Latino boys, masculinity and the abjection of homosexuality. Gender and Education, 25, 340-356. doi: 10.1080/09540253.2012.757298

Najmabadi, A. (2011). Verdicts of science, rulings of faith: Transgender/sexuality in contemporary Iran. Social Research, 78, 533-556.

Neisen, J.H. (1990). Heterosexism: redefining homophobia for the 1990s. Journal of Gay and Lesbian Psychotherapy, 1(3), 21-35. doi: 10.1300/J236v01n03_02

O'Conor, A. (1995). Who gets called queer in school? In G. Unks (Ed.), The gay teen:

Educational practice and theory for lesbian, gay and bisexual youth (pp. 95-101). New York: Routledge.

Pascoe, C.J. (2007). Dude, you're a fag: masculinity and sexuality in high school. Berkeley: University of California Press.

Plant, R. (1988). The Pink Triangle: the Nazi war against homosexuals. New York: Henry Holt Co. 
Plummer, D. (1999). One of the boys: masculinity, homophobia and modern manhood. New York: Haworth Press.

Plummer, D. (2001a). The quest for modern manhood, Journal of Adolescence, 24, 15-23. doi: 10.1006/jado.2000.0370

Plummer, D. (2001b). Policing manhood. In C. Wood (Ed.), Sexual Positions: An Australian view (pp. 60-75). Melbourne: Hill of Content / Collins.

Plummer, D. (2005). Crimes against manhood: Homophobia as the penalty for betraying hegemonic masculinity. In G. Hawkes, \& J. Scott (Eds.), Perspectives in human sexuality (pp. 218-232). Melbourne: Oxford University Press.

Plummer, D. (2007). Homophobia, heterosexism and beyond. In M. Flood, J.K. Gardiner, B. Pease \& K. Pringle (Eds.), International Encyclopaedia of Men and Masculinities, (vol 1). London: Routledge.

Plummer, D. (2009). How risk and vulnerability become 'socially embedded': Insights into the resilient gap between awareness and safety in HIV. In C. Barrow, M. de Bruin, \& R. Carr (Eds.), Sexuality, social exclusion \& human rights: Vulnerability in the Caribbean context of HIV (pp. 239-256). Kingston: Ian Randle Publishing.

Plummer, D. (2013). Masculinity and risk: how gender constructs drive sexual risks in the Caribbean. Sexuality Research and Social Policy, 10, 163-174. doi: 10.1007/s13178-013-0116-7

Plummer, D., \& Geofroy, S. (2010). When bad is cool: violence and crime as rites of passage to manhood. Caribbean Review of Gender Studies, 4. Retrieved from http://www2.sta.uwi.edu/crgs/february2010/journals/PlummerGeofory.pdf

Plummer D., McLean A., \& Simpson J. (2008). Has learning become taboo and is risk-taking compulsory for Caribbean boys? Caribbean Review of Gender Studies, 2. Retrieved from http://sta.uwi.edu/crgs/ september2008/journals/DPlummerAMcleanJSimpson.pdf

Reddock, R. E. (Ed.). (2004). Interrogating Caribbean masculinities. Mona, Jamaica: University of the West Indies Press.

Reddock, R. (2009). Feminist research and theory: Contributions from the Anglophone Caribbean. In C.E. Bose \& M. Kim (Eds.), Global gender research: Transnational perspectives (Chapter 18). New York: Routledge.

Schmitt, A. \& Sofer, J. (eds.) (1992). Sexuality and eroticism among males in Moslem societies. New York: Harrington Park Press.

Shakhsari, S. (2012). From homoerotics of exile to homopolitics of diaspora. Cyberspace, the war on terror and the hypervisible Iranian queer. Journal of Middle East Women's Studies, $8(3), 14-40$.

Stop Murder Music. (2004). Dancehall Dossier. Outrage! Retrieved from http://outrage.org.uk/wp-content/uploads/2010/05/Dancehall-Dossier-FULL.pdf 
Tasca, C., Rapetti, M., Carta, M.G., \& Fadda, B. (2012). Women and hysteria in the history of mental health. Clinical Practice and Epidemiology in Mental Health, 8, 110-119. doi: $10.2174 / 1745017901208010110$

Tin, L-G. (ed.) (2008). The Dictionary of Homophobia: a global history of gay and lesbian experience. Vancouver: Arsenal Pulp Press.

Trumble, W.R. (2007). Shorter Oxford English Dictionary (6 ${ }^{\text {th }}$ Ed.). Oxford: Oxford University Press.

UNAIDS. (2013). Global report: UNAIDS report on the global AIDS epidemic 2013. Geneva: Joint United Nations Programme on HIV/AIDS (UNAIDS).

Underwood, A.E.M. (2011). The politics of pride: the LGBT movement and post-Soviet democracy. Harvard International Review, 33, 42-46.

Weinberg, G. (1972). Society and the Healthy Homosexual. Boston: Alyson Publications.

West, K., \& Cowell, N.M. (2014). Predictors of Prejudice against Lesbians and Gay Men in Jamaica. The Journal of Sex Research. doi: 10.1080/00224499.2013.853725

Xie, N. (2010). Legislating hatred: anti-gay sentiment in Uganda. Harvard International Review, 32, 6. Retrieved from http://hir.harvard.edu/women-in-power/legislating-hatred 